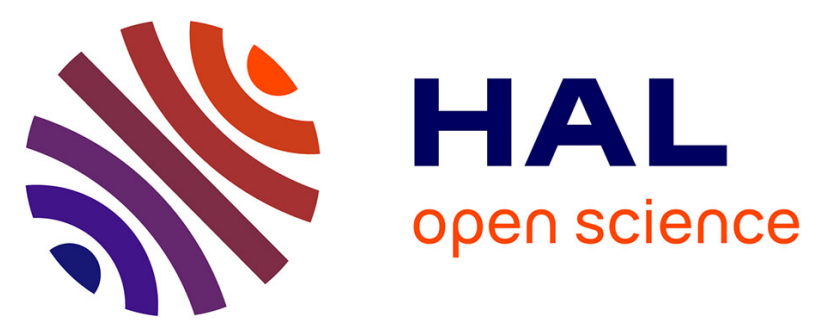

\title{
First study on the release of a natural antimicrobial agent, estragole, from freeze-dried delivery systems based on cyclodextrins and liposomes
}

Riham Gharib, Souha Haydar, Catherine Charcosset, Sophie Fourmentin, Hélène Greige-Gerges

\section{To cite this version:}

Riham Gharib, Souha Haydar, Catherine Charcosset, Sophie Fourmentin, Hélène Greige-Gerges. First study on the release of a natural antimicrobial agent, estragole, from freeze-dried delivery systems based on cyclodextrins and liposomes. Journal of Drug Delivery Science and Technology, 2019, 52, pp.794-802. 10.1016/j.jddst.2019.05.032 . hal-03033861

\section{HAL Id: hal-03033861 https://hal.science/hal-03033861}

Submitted on 9 Dec 2020

HAL is a multi-disciplinary open access archive for the deposit and dissemination of scientific research documents, whether they are published or not. The documents may come from teaching and research institutions in France or abroad, or from public or private research centers.
L'archive ouverte pluridisciplinaire HAL, est destinée au dépôt et à la diffusion de documents scientifiques de niveau recherche, publiés ou non, émanant des établissements d'enseignement et de recherche français ou étrangers, des laboratoires publics ou privés. 
1 First study on the release of a natural antimicrobial agent, estragole, from freeze-

4 Riham Gharib ${ }^{\mathrm{a}, \mathrm{b}, \mathrm{c}}$, Souha Haydar ${ }^{\mathrm{a}}$, Catherine Charcosset ${ }^{\mathrm{b}}$, Sophie Fourmentin ${ }^{\mathrm{c}}$, Hélène

5 Greige-Gerges ${ }^{\mathrm{a}^{*}}$

6 aioactive Molecules Research Laboratory, Faculty of Sciences, Doctoral School of

7 Sciences and Technologies, Lebanese University, Lebanon.

8 baboratoire d'Automatique et de Génie des Procédés, Université Claude Bernard Lyon

9 1, UMR 5007, CNRS, CPE, 43 bd du 11 Novembre, 691622 Villeurbanne Cedex, France

$10{ }^{c}$ Unité de Chimie Environnementale et Interactions sur le Vivant (UCEIV), EA 4492 SFR

11 Condorcet FR CNRS 3417, Université du Littoral-Côte d'Opale, 59140 Dunkerque,

12 France.

13 *Corresponding author: Hélène Greige-Gerges, Professor, Faculty of Sciences, Section

14 II, Bioactive Molecules Research Laboratory, Lebanese University, B.P. 90656, Jdaidet

15 El-Matn, Lebanon. Tel: 961-3 341011. E-mail: greigegeorges@ yahoo.com;

16 hgreige@ul.edu.lb

18 E-mail address: hgreige@ul.edu.lb (H. Greige-Gerges); lamotte@univ-littoral.fr (S.

19 Fourmentin); charcosset@lagep.univ-lyon1.fr (C. Charcosset); shaydar@ul.edu.lb (S.

20 Haydar) and gharib_riham@hotmail.com (R. Gharib). 


\section{Abstract}

23 Estragole is considered as a promising candidate for food preservation due to its

24 antioxidant and antimicrobial properties. However, its sensitivity to light and oxygen, its

25 volatility and hydrophobicity prevent its large application. In order to increase the

26 stability of estragole, conventional liposomes (CL) and drug-in-cyclodextrin-in-

27 liposomes (DCL) were prepared by the ethanol-injection method using Phospholipon

$2890 \mathrm{H}$ in combination with cholesterol and then freeze-dried using hydroxypropyl- $\beta-$

29 cyclodextrin (HP-ß-CD) as a cryoprotectant. Fresh and reconstituted vesicles

30 demonstrated nanometric vesicles size, spherical shape and negative surface charge.

31 Moreover, all suspensions were homogeneous. Compared to CL, DCL improved

32 estragole encapsulation efficiency, and conserved the same loading rate during freeze-

33 drying. Freeze-dried CL and DCL retained estragole more efficiently compared to the

34 reconstituted ones, as evidenced by release study performed by multiple headspace

35 extraction. Finally, we demonstrated, for the first time, that HP-B-CD did not affect the

36 membrane fluidity of fresh and reconstituted Phospholipon 90H/cholesterol CL and DCL.

38 Keywords: conventional liposomes; drug-in-cyclodextrin-in-liposomes; estragole;

39 freeze-drying; hydroxypropyl-ß-cyclodextrin. 


\section{$40 \quad 1$ Introduction}

41 Estragole (Est), 4-methoxyallylbenzene, is a natural phenylpropene found in many

42 aromatic plants. It is a constituent of tarragon (60-75\%), basil (2-43\%), star anise (5-6\%),

43 and fennel (5-20\%) essential oils [1]. Estragole is Generally Recognized As Safe (GRAS)

44 and approved by the Expert Panel of the Flavor and Extract Manufacturer's Association

45 (FEMA, USA) that concluded that the dietary intake of estragole from the consumption

46 of spices do not pose a health risk [2]. Estragole has a taste described as spice, cinnamon,

47 mouth tingle, fresh, peppery and woody. It is used for the modification of spice flavors

48 and seasonings for condiments and meats as well as in heavy fruit, root beer and anise-

49 type flavors [2] as well in teas to prevent flatulence and spasms. Moreover, estragole

50 exhibits myorelaxant, anticonvulsant, anesthetic, bradycardic, vasoactive and

51 antioxidative properties [2-4]

52 Estragole proved an antifungal activity against Aspergillus niger, A. flavus, Trichoderma

53 viride, Candida albicans, C. utilis, C. tropicalis, Cryptococcus neoformans, Trichophyton

54 mucoides, T. tonsurans, and Blastoschizomyces capitatus [6,7]. In addition, estragole

55 presented fairly significant zones of inhibition against Gram-positive bacteria [8].

56 Widespread application of estragole is limited by its volatility and poor water solubility.

57 Moreover, external factors such as temperature, light, and accessibility to atmospheric

58 oxygen affect the stability of estragole [9]. For example, the photooxidation of estragole

59 produced 4-methoxybenzaldehyde (anisaldehyde) and 4-methoxybenzene acetaldehyde

60 [10]. Attempts were made to increase the stability of essential oil containing estragole

61 through encapsulation of basil oil in gelatin microcapsules [11, 12], in nano- and micro-

62 emulsion [12, 14] or in cyclodextrins (CD) [15-17]. CDs increased the solubility and 
63 photostability of estragole (3-12 and 6-18 fold, respectively, depending on CD type) and 64 also maintained its bioactivity.

65 Liposomes are viewed as attractive novel materials by the food and medical industries.

66 Interest in liposome has increased due to their reported functional properties, including

67 their efficient encapsulation capacity, biocompatibility with food constituents and low

68 cost of raw materials used for manufacturing [18-21]. However, the main obstacle to the

69 use of liposomes is oxidation of lipids during storage. The presence of water may favor

70 bacterial growth and promote phospholipid degradation. Therefore, a way to stabilize

71 them is to use freeze-drying process. Unfortunately, lyophilization itself can alter the

72 liposome membrane bilayer. Therefore, it must be conducted according to a defined

73 protocol and with added excipients that preserve the bilayer structure [22].

74 The type of phospholipid and the presence of cholesterol in the bilayer affect the stability

75 of liposome structure during lyophilization in addition to the cryoprotector [23].

76 Cholesterol is often included in liposome composition because it can modulate the

77 physicochemical properties of the lipid bilayer by disordering the gel state of the lipid

78 bilayer or ordering the liquid state [24]. Lyophilization of liposomes without addition of

79 cryoprotectants provokes their coalescence and aggregation. It has been demonstrated

80 that hydroxypropyl- $\beta$-cyclodextrin (HP- $\beta-C D)$ maintains the physical and chemical

81 stability of conventional liposomes made from Phospholipon 90H during freeze-drying.

82 Moreover, the presence of HP- $\beta-C D$ in the aqueous phase of DCL system showed a

83 protective effect during freeze-drying [25].

84 We recently studied the encapsulation of essential oil components in conventional

85 liposomes and in drug-in-CD-in-liposome (DCL). This system, combining the relative 
86 advantages of both carriers [26], improved the encapsulation of essential oil components

87 such as trans-anethole [27, 28] and eugenol [29] and reduced drug release compared to

88 conventional liposomes [28].

89 In the present study, different CL and DCL formulations containing estragole were

90 prepared by ethanol injection method using hydrogenated phospholipid in presence of

91 cholesterol. These liposomes formulations were characterized before and after freeze-

92 drying. The size, polydispersity index, zeta potential of liposomes formulations were

93 determined as well as the morphology using transmission electron microscopy. The

94 loading rate of estragole was determined using HPLC. The stability of vesicles was

95 assessed after 6 months of storage at $4^{\circ} \mathrm{C}$ in powder form and the release of estragole

96 from the inclusion complex, CL and DCL was studied by multiple headspace extraction

97 at $60^{\circ} \mathrm{C}$. The volatility of estragole and the fluidity of the membrane may affect the

98 estragole encapsulation. Hence, the Henry's law constant of estragole was determined at

9930 and $60^{\circ} \mathrm{C}$, and the fluorescence anisotropy of 1,6-diphenylhexatriene (DPH) inserted

100 in the lipid membranes of CL and DCL was studied for the first time before and after

101 freeze-drying at 25 and $37^{\circ} \mathrm{C}$.

\section{Materials and methods}

\section{$103 \quad 2.1 \quad$ Materials}

104 Hydrogenated phospholipon $90 \mathrm{H} \quad(90 \%$ soybean phosphatidylcholine, $4 \%$ 105 lysophosphatidylcholine, $2 \%$ triglycerides, $2 \%$ water, $0.5 \%$ ethanol, $1 \%$ iodine) was 106 supplied by Lipoid GmbH (Ludwigshafen, Germany). HP- $\beta$-CD-oral grade (MS=0.85)

107 was obtained from Roquette (Lestrem, France), thymol, absolute ethanol, cholesterol and 
108 methanol-HPLC grade were from Sigma-Aldrich (Germany) and estragole was purchased

109 from Sigma-Aldrich (China). Water was purified on a Milli-Q system obtained from a

110 Millipore ${ }^{\circledR}$ synergy system (Millipore, Billerica, Massachusetts, USA).

111

\section{2.2 Preparation of HP-ß-CD/Est inclusion complex}

113

$1147.44 \mathrm{mg}$ of estragole was added to $5 \mathrm{~mL}$ HP-ß-CD solutions $(0,10,25,50,75$ and 100

$115 \mathrm{mM}$ ). The mixtures were shaken at $25{ }^{\circ} \mathrm{C}$ for $24 \mathrm{~h}$ then filtered through a $0.45 \mu \mathrm{m}$

116 membrane filter. The concentrations of estragole in the filtrates were determined by the

117 HPLC method described below.

118

119 The complexation efficiency was calculated using the following equation:

$$
C E_{C D}(\%)=\frac{m E s t_{\text {exp }}}{m E s t_{i}} \times 100(1)
$$

120 where $m$ Est $_{\text {exp }}$ is the mass of estragole experimentally determined by HPLC in the

121 inclusion complex solution and $\mathrm{m} \mathrm{Est}_{\mathrm{i}}$ is the mass of estragole initially used to prepare

122 the inclusion complex [30].

\section{$124 \quad 2.3$ Preparation of HP-B-CD/Est inclusion complex for DCL preparations}

126 HP-ß-CD was dissolved in ultrapure water and the required amount of estragole was

127 added to obtain HP-B-CD:Est molar ratio of 75:10 and 100:10; the concentration of HP-

$128 \beta-\mathrm{CD}$ were of 111 and $148 \mathrm{mg} / \mathrm{mL}$, respectively. The mixture was stirred (120 rpm for 24

$129 \mathrm{~h}$ at $25^{\circ} \mathrm{C}$ ), filtered through a $0.45 \mu \mathrm{m}$ membrane, and then used in DCL preparations. 


\section{$131 \quad 2.4 \quad$ Preparation of liposomes by ethanol injection method}

132

133

134

135

136 Germany), into the aqueous phase $(20 \mathrm{~mL})$ at $55^{\circ} \mathrm{C}$ (temperature above the transition

137 temperature of Phospholipon 90H) under magnetic stirring at $400 \mathrm{rpm}$. Spontaneous

138 liposome formation occurred as soon as the ethanolic solution was in contact with the 139 aqueous phase. The liposomal suspension was then left for 15 min at $25^{\circ} \mathrm{C}$ under stirring 140 (400 rpm). Finally the ethanol was removed by rotary evaporation (BÜCHI Rotavapor R141 100) under reduced pressure at $40{ }^{\circ} \mathrm{C}$. Four batches were prepared: 1) blank-CL; 2)

142 blank-DCL, where HP-B-CD was dissolved in the aqueous phase at concentrations of 75 143 (blank-DCL 75) and $100 \mathrm{mM}$ (blank-DCL 100); 3) Est-loaded liposomes (Est-CL), where 144 estragole was added in the organic phase at a concentration of $2.5 \mathrm{mg} / \mathrm{mL}$; 4) HP- 3 $145 \mathrm{CD} /$ Est inclusion complex-loaded liposomes (Est-DCL), where the HP-B-CD/Est solution 146 prepared previously (Est-DCL 75 and Est-DCL 100 correspond to DCL preparation using 147 HP-ß3-CD:Est molar ratio of 75:10 and 100:10, respectively). Each batch was prepared in 148 triplicate and underwent characterization as described below.

\section{$150 \quad 2.5 \quad$ Freeze-drying}

151 Freshly prepared blank-CL, blank-DCL, Est-CL, Est DCL 75 and Est DCL 100 (5 mL) 152 underwent ultracentrifugation at $170000 \mathrm{~g}$ for $1 \mathrm{~h}$ at $4{ }^{\circ} \mathrm{C}$. The supernatant was discarded 153 and the pellet was reconstituted in $2 \mathrm{~mL}$ of water or $\mathrm{HP}-\beta-\mathrm{CD}$ solution ( 25 and $50 \mathrm{mM}$ ) 154 for $\mathrm{CL}$ or in $2 \mathrm{~mL}$ of HP-ß-CD solution of 75 or $100 \mathrm{mM}$, for Est-DCL 75 and Est- 
155 DCL100, respectively. The liposomes suspensions and the inclusion complex HP-ß-

$156 \mathrm{CD} /$ Est molar ratio of 75:10 and 100:10 were freeze-dried according to the protocol

157 described in our previous study [25]. Finally, the vials were removed from the freeze-

158 dryer, closed with rubber caps and stored at $4{ }^{\circ} \mathrm{C}$. The lyophilized liposomes were then

159 reconstituted with ultra-pure water to its original volume $(5 \mathrm{~mL})$ prior to characterization

160 and further analysis.

161

\section{$162 \quad 2.6 \quad$ Liposome characterization}

\section{2.6.1 Dynamic Light Scattering Analysis}

164 Malvern Zetasizer Nanoseries (Zetasizer Nano ZS; Malvern Instruments Ltd, France) was

165 used to determine the mean size of liposome batches, its range of detection is between 30

$166 \mathrm{~nm}$ and $10 \mu \mathrm{m}$. All batches were diluted 10-fold with ultrapure water. The particle size

167 distribution data were collected using the DTS (nano) software (version 5.10) provided

168 with the instrument. The polydispersity index (PdI), which gives an indication of the

169 width of particle size distribution, ranges from 0 (monodispersed) to 1 (very broad

170 distribution). Data were expressed as the mean \pm standard deviation. Zeta potential was

171 calculated by Smoluchowski's equation from the electrophoretic mobility of liposomes.

172 All measurements were carried out at $25{ }^{\circ} \mathrm{C}$ after $3 \mathrm{~min}$ of equilibration and performed in 173 triplicate.

174

175 2.6.2 Morphological characterization by transmission electron microscopy

176 Blank-DCL 75, blank-DCL 100, Est-DCL 75 and Est-DCL 100 before and after freeze- 
177 drying were imaged with transmission electron microscope (TEM) (CM 120; Philips,

178 Eindhoven, Netherlands) operating at an accelerating voltage of $120 \mathrm{kV}$. A drop of

179 liposomes was placed onto a carbon-coated copper grid for $3 \mathrm{~min}$; the excess suspension

180 was removed with a filter paper, leaving a thin liquid film stretched over the pores.

181 Negative staining using a sodium silicotungstate solution (1\%) was directly made on the

182 deposit over $30 \mathrm{~s}$. The excess sodium silicotungstate solution was then removed with a

183 filter paper and the stained samples were examined.

184 2.6.3 Determination of encapsulation efficiency and loading rate for estragole in $185 \quad$ liposomes

186 The EE of estragole into liposomes was determined upon HPLC analysis of free and total

187 estragole present in the liposome suspensions. Aliquots were removed from the liposomal

188 suspension to determine the total estragole concentration ([Est $\left.]_{\text {Total }}\right)$. The liposomal 189 suspension underwent ultracentrifugation (Optima ${ }^{\mathrm{TM}}$ Ultracentrifuge, Beckman Coulter,

$190 \mathrm{USA}$ ) at $170000 \mathrm{~g}$ for $1 \mathrm{~h}$ at $4{ }^{\circ} \mathrm{C}$. Aliquots were removed from the supernatant to

191 determine the concentration of free Est $\left([\text { Est }]_{\mathrm{F}}\right)$. EE of Est was calculated as follows:

$$
E E(\%)=\frac{[\text { Est }]_{T o t}-[\text { Est }]_{F}}{[\text { Est }]_{T o t}} \times 100(2)
$$

192 where $[\text { Est }]_{\text {Tot }}$ and $[\text { Est }]_{\mathrm{F}}$ corresponds to the concentration of total and free estragole,

193 determined by the HPLC method described below, respectively.

195 The LR of estragole was calculated by the following equation:

$$
L R=\frac{m_{\text {liposomal suspension }}-m_{\text {filtrate }}}{m_{\text {Initial }}} \times 100(3)
$$


198 The LR after freeze-drying was calculated using the following equation:

$$
L R_{f d}=\frac{m_{\text {reconstituted liposomes }}}{m_{\text {Initial }}} \times 100
$$

200 where $\mathrm{m}_{\text {initial }}$ for Est-DCL is the initial mass of estragole used to prepare CD/Est inclusion

201 complex. For Est-CL, $\mathrm{m}_{\text {initial }}$ is the initial mass of estragole added to the organic phase

202 during liposome preparation. $\mathrm{m}_{\text {reconstituted liposomes }}$ is the mass of estragole found in the

203 aqueous phase after freeze-drying and reconstitution of liposome.

\subsection{HPLC assay of estragole}

Stock standard solutions of estragole $(1 \mathrm{mg} / \mathrm{mL})$ and of the internal standard, thymol (1

$208 \mathrm{mg} / \mathrm{mL}$ ) were prepared in methanol. Aliquots were removed from the estragole stock

209 solution and diluted in methanol to obtain final concentrations of estragole ranging from

2101 to $250 \mu \mathrm{g} / \mathrm{mL}$. The diluted solution of thymol $(100 \mu \mathrm{g} / \mathrm{mL})$ was prepared in methanol.

211 Two hundred $\mu \mathrm{L}$ of each filtrate (aqueous solution of HP-ß-CD/ Est inclusion complex)

212 were added to $200 \mu \mathrm{L}$ of thymol $(100 \mu \mathrm{g} / \mathrm{mL})$ and $400 \mu \mathrm{L}$ of methanol. The samples

213 were sonicated for $10 \mathrm{~min}$ at room temperature. The samples were analyzed by HPLC

214 (Agilent Technologie 1200 series) using an analytical column C18 $15 \mathrm{~cm}$ x $4.6 \mathrm{~mm}, 5$

$215 \mu \mathrm{m}$, (Agilent Technologies). The mobile phase was a mixture of methanol and water

216 (70/30). The flow rate was fixed at $1 \mathrm{~mL} / \mathrm{min}$ and the detection was set at $206 \mathrm{~nm}$.

217 The retention times of thymol (internal standard) and estragole were 5.7 and $8.4 \mathrm{~min}$,

218 respectively. Calibration curves were constructed by plotting the estragole/thymol area

219 ratio against the concentration of estragole in $\mu \mathrm{g} / \mathrm{mL}$. The linear relationships were

220 evaluated by regression analysis with the least squares method and the correlation 
221 coefficient ranged from 0.996 to 0.999 .

\subsection{Fluorescence anisotropy measurements}

225 To evaluate the effect of estragole, HP- $\beta-C D$ and freeze-drying on the membrane fluidity

226 of vesicles composed of phospholipon 90H:cholesterol, steady state fluorescence

227 polarization technique using a Cary Eclipse Fluorescence Spectrophotometer (Agilent

228 Technologies) was used. DPH was dissolved in tetrahydrofuran $\left(4.3010^{-3} \mathrm{~mol} / \mathrm{L}\right)$ then an

229 aliquot was added to the vesicles suspension (blank-CL, blank-DCL 75, blank-DCL 100,

230 Est-CL, Est-DCL 75 and Est-DCL 100) to obtain DPH:phospholipid molar ratio of 1:500.

231 The mixture was incubated overnight in the dark to allow the intercalation of the DPH

232 molecules into the lipid bilayer. The final concentration of THF did not exceed $0.01 \%$

233 and showed no effect on the fluorescence anisotropy [31]. The experiments were

234 performed at 25 and $37{ }^{\circ} \mathrm{C}$. The probe was excited with a manual polarizer accessory

235 (Cary Eclipse Manual Polarizer, Agilent Technologies; Malaysia) using vertically

236 polarized light at $360 \mathrm{~nm}$. The emission intensities were measured at $450 \mathrm{~nm}$ at both

237 parallel and perpendicular to the polarization vector of the exciting light yielding

238 components $\mathrm{I}_{\mathrm{Vv}}$ and $\mathrm{I}_{\mathrm{VH}}$, respectively. The Cary Eclipse Bio Software, delivered from the

239 spectrophotometer, gives the fluorescence anisotropy (R), which is defined as

$$
R=\frac{I_{\|}-I_{\perp}}{I_{\|}+2 I_{\perp}}
$$

240 where $I_{\|}$and $I_{\perp}$ are the fluorescence intensities of the light emitted with its polarization 241 plane parallel $(\|)$ and perpendiculaire $(\perp)$ to that of the exciting beam. 


\section{$243 \quad 2.9 \quad$ Release study}

244

245 Multiple headspace extraction (MHE) is a dynamic gas extraction carried out stepwise

246 [32]. At each step, equilibrium conditions are established in the vial between the sample

247 and its gas phase. The vials containing free estragole, Est-CL, Est-DCL 75, Est-DCL 100

248 or the inclusion complex (HP-ß-CD/Est molar ratio of 75:10 and 100:10) were submitted

249 to 24 successive gas extractions at constant interval $(8 \mathrm{~min})$ in the same operating

250 conditions. At each extraction, $1 \mathrm{ml}$ of the vapor from the headspace of the solution was

251 withdrawn from the vial using a gas-tight syringe and injected in the chromatographic

252 column via a transfer line. All measurements were conducted with an Agilent G1888

253 headspace sampler coupled to a Perkin Elmer Autosystem XL gas chromatography

254 equipped with a flame ionization detector and a DB624 column. Headspace operating

255 conditions were as follows: oven temperature of $60^{\circ} \mathrm{C}$, transfer line temperature of $250^{\circ} \mathrm{C}$

256 and nitrogen as carrier vector. GC conditions were as follows: column temperature of

$257 \quad 160^{\circ} \mathrm{C}$ and $\mathrm{GC}$ cycle of $8 \mathrm{~min}$.

$259 \quad 2.9 .1 \quad$ Release of estragole

260 After 6 months of storage of $\mathrm{CL}$ and $\mathrm{DCL}$ at $4^{\circ} \mathrm{C}$, the release of estragole from freeze-

261 dried CL and DCL as well as from reconstituted powders was studied by MHE coupled

262 to gas chromatography. Est-CL, Est-DCL 75 or Est-DCL 100 in powder form (10 mg),

263 Est-CL, Est-DCL 75, Est-DCL 100, HP-ß-CD/Est 75:10, HP-ß-CD/Est 100:10 inclusion

264 complex solutions and estragole $(0.5 \mathrm{mg} / \mathrm{mL})$ were placed in $22 \mathrm{ml}$ sealed vials. After

265 equilibrium, the release of estragole at time t was calculated as follows: 
267 Where, $A_{t}$ and $A_{0}$ corresponds to the area of the chromatographic peak of estragole at 268 time $t$ and at the first extraction, respectively. The plot of $\ln \left(A_{t} / A_{0}\right)$ as a function of time

269 followed a first-order release kinetics. The release rate constant $\mathrm{K}\left(\mathrm{min}^{-1}\right)$ was calculated 270 using the following equation:

$$
\operatorname{Ln}\left(A_{t} / A_{0}\right)=-\operatorname{Kt}(7)
$$

\subsubsection{Loading capacity determination}

273 The amount of estragole in the inclusion complex HP-ß-CD/Est, CL and DCL was

274 determined after 6 months of storage at $4^{\circ} \mathrm{C}$ in powder form using MHE. The 275 concentration of the analyte in the gas phase of the vial decreases at each extraction step.

276 Thus, the sum of the amounts of the analyte removed in the individual extractions will be 277 equal to the total amount of analyte present in the original sample [32].

278 A linear regression was constructed for the standard and the samples using the following 279 equation:

$$
\ln \mathrm{A}_{\mathrm{t}}=-\mathrm{q}(\mathrm{t}-1)+\ln \mathrm{A}_{1}(8)
$$

282 where $A_{1}$ is the area of the chromatographic peak of estragole at the first extraction; $A_{t}$ is 283 the peak area of estragole at the extraction $t$ and $-\mathrm{q}$ is the slope of the regression curve 284 that illustrates $\ln A_{t}$ as a function of $(t-1)$.

285 Q is a constant parameter calculated as follows:

$$
Q=e^{-q}(9)
$$

287 The sum of peak areas corresponding to the total amount of estragole present in the 288 sample or in the standard are obtained as follows: 


$$
\sum A_{t}=\frac{A_{1}}{1-Q}(10)
$$

290 The amount of estragole in the IC is calculated using the following relation:

$$
E_{\text {st }} t_{\text {exp }}(m g)=\frac{\sum A_{\text {sample }}}{\sum A_{\text {standard }}} \times S t d(m g)
$$

292 where $\sum \mathrm{A}_{\text {sample }}$ and $\sum \mathrm{A}_{\text {standard }}$ are the sum of peak areas of estragole corresponding to the

293 sample and the external standard, respectively; Std is the amount of the standard (0.005

$294 \mathrm{mg})$.

295 Loading capacity ( $\mathrm{LC} \mathrm{m}_{\mathrm{Es}} / \mathrm{m}_{\text {powder }}$ ) of estragole is expressed as $\mathrm{mg}$ of encapsulated 296 estragole per gram of the powder of the delivery system.

$$
L C\left(m_{E s t} / m_{\text {powder }}\right)=\frac{E s t_{\text {exp }}(m g)}{\text { mass of powder }(m g)}(12)
$$

\subsection{Determination of Henry's law constant of estragole}

300

301 The Henry's law constant $\left(\mathrm{H}_{\mathrm{c}}\right)$ is the vapor-liquid partition coefficient expressed as 302 followed [32]:

$$
H_{C}=\frac{C_{G}}{C_{L}}
$$

303 where $\mathrm{C}_{\mathrm{G}}$ is the concentration of estragole in the vapor phase and $\mathrm{C}_{\mathrm{L}}$, the concentration of

304 estragole in the aqueous phase.

305 The value of $\mathrm{H}_{\mathrm{C}}$ for estragole was determined experimentally by static headspace-gas 306 chromatography (SH-GC) at two temperatures $\left(30\right.$ and $60^{\circ} \mathrm{C}$ ). The $\mathrm{GC}$ column 307 temperature was set at $160{ }^{\circ} \mathrm{C}$. The headspace settings were as follows: an oven 308 temperature of 30 or $60{ }^{\circ} \mathrm{C}$ and an equilibrium time of $30 \mathrm{~min}$. The transfer line 309 temperature was set at $250{ }^{\circ} \mathrm{C}$. 
310 For the determination of $\mathrm{H}_{\mathrm{C}}$ in water, several headspace vials were prepared containing

311 different amounts of water $(0.5 ; 0.6 ; 1,2,3$ and $5 \mathrm{~mL})$ to which the same amount of

312 estragole was added (10 $\mu \mathrm{L}$ from a standard solution of $10000 \mathrm{ppm})$. Using essentially

313 the phase ratio variation method as described by Kolb and Ettre [32], the values of $\mathrm{H}_{\mathrm{C}}$

314 were determined by the relationship between the reciprocal chromatographic peak areas

315 and the vapor-liquid volumetric ratio $\left(\mathrm{V}_{\mathrm{G}} / \mathrm{V}_{\mathrm{L}}\right.$, with $\mathrm{V}_{\mathrm{G}}$ and $\mathrm{V}_{\mathrm{L}}$ being the vapor volume

316 and the liquid volume, respectively):

$$
\frac{1}{A V_{L}}=\frac{1}{\alpha} \frac{V_{G}}{V_{L}}+\frac{1}{\alpha H_{C}}
$$

317 where $\mathrm{A}$ is the peak area, $\alpha$ is a constant incorporating several parameters and $\mathrm{H}_{\mathrm{C}}$ is the

318 vapor-liquid partition coefficient, directly calculated from the ratio of the slope and

319 intercept of the fit of the experimental data obtained after allowing a vapor-liquid 320 equilibrium time of $30 \mathrm{~min}$ in the oven.

\section{$322 \quad 2.11$ Statistical analysis}

324 Statistical analysis was performed using the Student's t-test. $P$ values equal or less than

3250.05 were considered statistically significant.

\section{$327 \quad 3 \quad$ Results and discussion}

\section{$328 \quad 3.1 \quad$ HP-ß3-CD/estragole inclusion complex}

329 The HP- $\beta-C D$ concentration able to solubilize the initial amount of estragole (7.44 mg)

330 was determined; a complete solubilization of this mass leads to a solution containing 
331 estragole $(10 \mathrm{mM})$. Figure 1 shows the variation of estragole concentration in $\mathrm{CD} / \mathrm{Est}$

332 inclusion complex solution at various HP- $\beta-C D$ concentrations. In the absence of $C D$, the

333 concentration of estragole was $17.73 \pm 2.82 \mu \mathrm{g} / \mathrm{ml}$. As we can see, a CD concentration of

$334100 \mathrm{mM}$ was necessary to solubilize $7.44 \mathrm{mg}$ of estragole. Table 1 shows the

335 complexation efficiency of estragole at various $\mathrm{HP}-\beta-\mathrm{CD}$ concentrations. The $\mathrm{CE}_{\mathrm{CD}}$

336 values were calculated using equation 1 . The $\mathrm{CE}_{\mathrm{CD}}$ value was $34 \%$ at $\mathrm{HP}-\mathrm{B}-\mathrm{CD}$ :Est molar

337 ratio of $10: 10$, then $\mathrm{CE}_{\mathrm{CD}}$ values increased with $\mathrm{HP}-\beta-\mathrm{CD}$ concentration, which is in

338 agreement with Kfoury et al. [16]. The $\mathrm{CE}_{\mathrm{CD}}$ values of estragole at HP- $\beta-\mathrm{CD}$ :Est molar

339 ratio of 75:10 and 100:10 were 91 and 100\%, respectively (Table 1). Consequently, the

340 HP-B-CD:Est molar ratios of 75:10 and 100:10 were used to prepare DCL batches. We

341 should mention that CDs at high concentration can perturb the liposomes membrane

342 properties and extract lipid components [33]. For that, we did not use a concentration of

343 HP-B-CD above $100 \mathrm{mM}$ as our aim was to develop the DCL system loading estragole.

344 Hence, the limitation of CD concentration and the solubilization of estragole were mainly

345 considered in the selection of CD:Est molar ratio.

346

347 


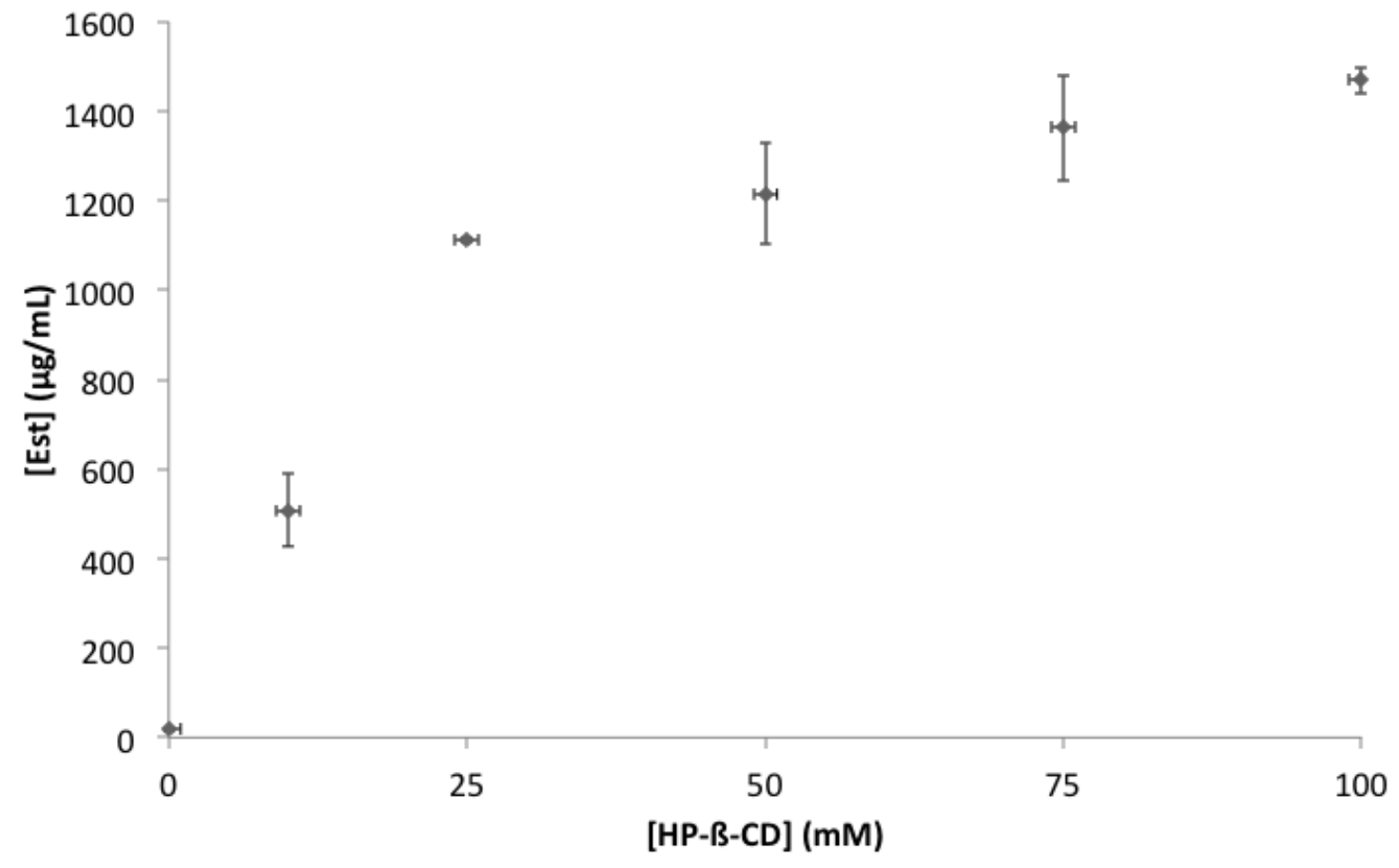

Figure 1: The variation of the concentration of estragole $(\mu \mathrm{g} / \mathrm{ml})$ with $\mathrm{CD}$ concentration.

350

351

352

353

354

355

356

357

358

359

360

361 terms of mean particle size, PdI and zeta potential values before and after freeze-drying,

\subsection{Mean size, pdI, zeta potential values of liposomes before and after}

\begin{tabular}{|l|l|}
\hline HP-B-CD :Est molar ratio & $\mathrm{CE}_{\mathrm{CD}}(\%)$ \\
\hline $10: 10$ & $34.12 \pm 5.41$ \\
\hline $25: 10$ & $74.78 \pm 0.29$ \\
\hline $50: 10$ & $81.65 \pm 21.75$ \\
\hline $75: 10$ & $91.56 \pm 7.97$ \\
\hline $100: 10$ & $98.76 \pm 2.32$ \\
\hline
\end{tabular}

Table 1: Complexation efficiency of estragole in HP- $\beta-C D$ as a function of CD concentration

freeze-drying

362 respectively and the results are listed in Table 2. 
363 Table 2: Size, polydispersity index, zeta potential values for fresh and reconstituted Est-CL and

364 Est-DCL from Phospholipon $90 \mathrm{H}$ before and after freeze-drying. The values obtained after

365 lyophilization were compared to those before lyophilization and * indicates a value of $\mathrm{P}<0.05$

366 statistically significant.

\begin{tabular}{|c|c|c|c|c|c|c|c|}
\hline & \multicolumn{3}{|c|}{ Before freeze-drying } & & \multicolumn{3}{|c|}{ After freeze-drying } \\
\hline & $\begin{array}{l}\text { Size } \\
(\mathbf{n m})\end{array}$ & pdI & Zeta $(\mathbf{m V})$ & $\begin{array}{c}\text { Dispersion of } \\
\text { the pellet } \\
\text { with }\end{array}$ & $\begin{array}{l}\text { Size } \\
(\mathbf{n m})\end{array}$ & pdI & $\begin{array}{l}\text { Zeta } \\
(\mathbf{m V})\end{array}$ \\
\hline \multirow{2}{*}{ Blank-CL } & \multirow{2}{*}{$179 \pm 10$} & \multirow{2}{*}{$0.08 \pm 0.01$} & \multirow{2}{*}{$-9.1 \pm 6.3$} & CD $25 \mathrm{mM}$ & $169 \pm 8$ & $0.22 \pm 0.04$ & $-7.4 \pm 1.7$ \\
\hline & & & & CD $50 \mathrm{mM}$ & $180 \pm 17$ & $0.15 \pm 0.02 *$ & $-5.0 \pm 4.0^{*}$ \\
\hline \multirow{2}{*}{ Est-CL } & \multirow{2}{*}{$176 \pm 2$} & \multirow{2}{*}{$0.10 \pm 0.2$} & \multirow{2}{*}{$-9.0 \pm 0.9$} & CD $25 \mathrm{mM}$ & $173 \pm 0.3$ & $0.14 \pm 0.01 *$ & $-6.4 \pm 0.2$ \\
\hline & & & & CD $50 \mathrm{mM}$ & $165 \pm 9$ & $0.14 \pm 0.01 *$ & $-2.4 \pm 1.6^{*}$ \\
\hline \multirow{2}{*}{$\begin{array}{c}\text { Blank-DCL } \\
75\end{array}$} & \multirow{2}{*}{$205 \pm 3$} & \multirow{2}{*}{$0.23 \pm 0.00$} & \multirow{2}{*}{$-10.7 \pm 1.4$} & Water & $201 \pm 2$ & $0.16 \pm 0.00 *$ & $-3.8 \pm 0.2^{*}$ \\
\hline & & & & CD $75 \mathrm{mM}$ & $198 \pm 3$ & $0.12 \pm 0.00$ & $-12.2 \pm 3.8$ \\
\hline Est-DCL 75 & $191 \pm 13$ & $0.28 \pm 0.07$ & $-6.8 \pm 6.2$ & CD $75 \mathrm{mM}$ & $187 \pm 3$ & $0.14 \pm 0.07$ & $-9.2 \pm 3.7$ \\
\hline \multirow{2}{*}{$\begin{array}{c}\text { Blank-DCL } \\
100\end{array}$} & \multirow{2}{*}{$210 \pm 17$} & \multirow{2}{*}{$0.31 \pm 0.01$} & \multirow{2}{*}{$-15.8 \pm 10.3$} & Water & $192 \pm 6.9$ & $0.16 \pm 0.03$ & $-8.2 \pm 0.1$ \\
\hline & & & & CD $100 \mathrm{mM}$ & $197 \pm 16$ & $0.21 \pm 0.07$ & $-10.1 \pm 3.8$ \\
\hline $\begin{array}{c}\text { Est-DCL } \\
100\end{array}$ & $188 \pm 19$ & $0.39 \pm 0.13$ & $-12.3 \pm 2.2$ & CD $100 \mathrm{mM}$ & $209 \pm 16$ & $0.14 \pm 0.00 *$ & $-11.7 \pm 4.5$ \\
\hline
\end{tabular}

368

369 Before freeze-drying, the analysis of particle size showed no significant difference

370 between the various formulations, since Est-CLs and Est-DCLs had similar range of

371 particle size of $(176-210 \mathrm{~nm})$. Thus the presence of HP-ß-CD or estragole did not affect

372 the liposome size. These results are in accordance with the literature [25, 28, 34, 35].

373 Besides, PdI values for all liposome formulations were less than 0.4 , suggesting that

374 liposomes suspensions were homogenous (Table 2). The presence of HP-ß-CD or

375 estragole did not affect the zeta potential values, which are negative ranging between (-6; 
$376-15 \mathrm{mV})$.

377

378 In a previous work, we evaluated the effect of hydrogenation and composition of soybean

379 phospholipids on the characteristics and the stability of blank-CL and blank-DCL during

380 freeze-drying [25]. The results showed that HP-ß-CD protect hydrogenated liposomes

381 (Phospholipon 90H:cholesterol or Phospholipon 80H:cholesterol formulation) during

382 freeze-drying. Furthermore, dispersing the pellet of CL in HP- $\beta-C D$ solution of (25 or 50

$383 \mathrm{mM}$ ), and dispersing the pellet of DCL in water or in HP- $3-\mathrm{CD}$ solution (at the same

384 concentration present in the internal aqueous phase of liposome) protect the structures

385 during freeze-drying. Here we applied the conditions to Est-CL and Est-DCL

386 formulations for freeze-drying.

387 As can be seen in Table 2, after freeze-drying the size, pdI and zeta potential values of

388 liposomes were maintained since no changes were observed for particle analysis before

389 and after freeze drying. These results demonstrate a successful freeze-drying of estragole

390 loaded Phospholipon 90H liposomes.

391

$392 \quad 3.3$ Encapsulation efficiency and loading rate values of estragole in

$393 \quad$ liposomes

394

395 The encapsulation efficiency (EE) and the loading rate (LR) values of estragole loaded

396 CL and DCL before and after freeze-drying were determined according to equations (2-4)

397 and the results are listed in Table 3.

398 

Est in fresh and reconstituted CL and DCL before and after freeze-drying.

\begin{tabular}{|c|c|c|c|}
\hline & \multicolumn{2}{|c|}{$\begin{array}{l}\text { Before freeze-drying } \\
\text { Fresh liposomes }\end{array}$} & \multirow{2}{*}{$\begin{array}{c}\begin{array}{c}\text { After freeze-drying } \\
\text { Reconstituted } \\
\text { liposomes }\end{array} \\
\mathbf{L R}_{\mathrm{fd}}(\%)\end{array}$} \\
\hline & EE (\%) & LR (\%) & \\
\hline Est-CL & ND* & $\mathrm{ND}^{*}$ & ND* \\
\hline Est-DCL 75 & $8.47 \pm 1.21$ & $1.58 \pm 0.25$ & $1.30 \pm 0.78$ \\
\hline Est-DCL 100 & $11.36 \pm 2.31$ & $3.25 \pm 0.68$ & $2.52 \pm 1.15$ \\
\hline
\end{tabular}

404 Before freeze-drying, the estragole concentration in CL formulations was under limit of 405 estragole detection by HPLC method, suggesting that Phospholipon 90H-CL were not 406 able to encapsulate estragole by ethanol injection method. The preparation of liposomes 407 requires heating at $55^{\circ} \mathrm{C}$, above the main transition temperature of Phospholipon $90 \mathrm{H}$, 408 which could induce the loss of volatile estragole during preparation. This is in line with $409 \mathrm{H}_{\mathrm{C}}$ value of estragole as it increased with temperature. The DCL carrier system improved 410 the estragole encapsulation. Indeed, the EE values of estragole were $8.47 \pm 1.21$ and $41111.36 \pm 2.31 \%$ for Est-DCL 75 and Est-DCL 100 respectively and the LR values of 412 estragole were $1.58 \pm 0.25$ and $3.25 \pm 0.68 \%$ for Est-DCL 75 and Est-DCL 100 413 respectively. In term of LR, DCL represents a better encapsulation system than CL for 414 numerous drugs including volatile ones such as trans-anethole [28] and non-volatile 415 compound like betamethasone [36]; celcoxib [37], curcumin [38] and indomethacin [39].

416 Besides, the amount of estragole in $\mathrm{CD} /$ drug inclusion complex solutions increased upon 417 increasing the HP- $\beta$-CD:Est molar ratio from $75: 10$ to 100:10. Same results were 418 observed by Maestrelli et al., [40], where the EE values of ketoprofen increased with 
419 increasing the concentration of HP-B-CD:ketoprofen inclusion complex when

420 encapsulated in the aqueous phase of liposomes.

421 After freeze-drying, the LR of estragole in Est-DCL 75 and Est-DCL 100 were quasi 422 maintained (Table 3).

\section{$424 \quad 3.4$ Morphology}

426 The TEM images showed the formation of nanometer-sized vesicles (Figure 2). The 427 images in Figure 2 (A-D) and (A'-D') are examples of blank-DCL 75, blank-DCL 100; 428 Est-DCL 75 and Est-DCL 100 obtained before and after freeze drying, respectively. The 429 TEM results are in agreement with the dynamic light scattering results since nanometric 430 sized vesicles appeared in the images. The vesicles are oligolamellar and spherical in 431 shape. CLs and DCLs loading estragole present similar structures to trans-anethole and 432 eugenol loaded CL and DCL [25, 29].
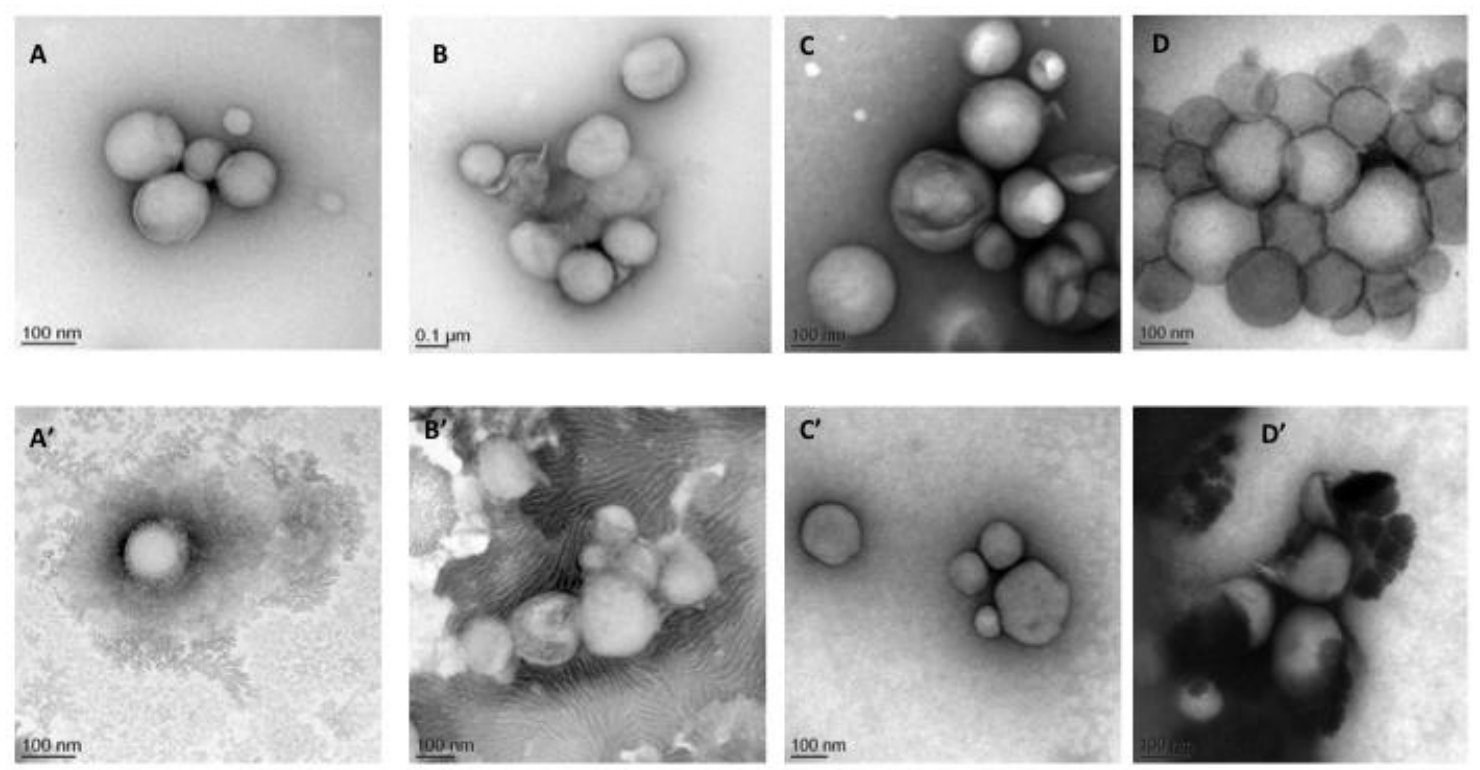
434 Figure 2: TEM images of Phospholipon 90H liposomes before freeze-drying: blank-DCL 75 (A); 435 blank-DCL 100 (B); Est-DCL 75 (C) and Est-DCL 100 (D) and after freeze drying: blank-DCL 43675 (A'); blank-DCL 100 (B'); Est-DCL 75 (C') and Est-DCL 100 (D').

\section{$438 \quad 3.5 \quad$ Release studies}

439 The release of volatile drugs from the samples (aqueous solution of a drug, delivery 440 systems incorporating a drug in liquid or powder form) can be tracked using MHE mode.

441 The procedure is well described by Kolb \& Ettre [32]. It consists in carrying out a 442 sampling sequence for the same sample. There is equilibrium between the sample and the 443 gas phase in the vial. At every extraction the headspace determined the concentration of 444 estragole in the gas phase. As the extractions proceed, the amount of the volatile guest 445 present in the headspace decreases to zero, as do the areas of the corresponding 446 chromatographic peaks. The sum of the areas obtained will therefore be equal to the

447 amount of guest present in the sample. The MHE therefore allows the illustration of the 448 release profile of the volatile product.

450 The release studies of estragole from freeze-dried HP-ß-CD/Est inclusion complex, Est-

$451 \mathrm{CL}$ and Est-DCL stored at $4^{\circ} \mathrm{C}$ for 6 months, were performed by the MHE method. The 452 estragole peak areas of the external standard ( $0.5 \mathrm{ppm}$ of estragole in water), inclusion 453 complex HP-ß-CD:Est (75:10 and 100:10 molar ratios in water) and estragole loaded 454 liposomes (CL and DCL in powder or reconstituted in water) are illustrated in.

455 The amount of estragole determined from powder samples (Est-CL, Est-DCL 75 and Est456 DCL 100, appeared in the insert of figure 3) was very low suggesting either high 457 retention of Est or weak presence of Est in all powder samples. For this reason, the 458 powders were dissolved in $10 \mathrm{ml}$ water and placed in sealed vials and analyzed by MHE. 
459 The results showed that the estragole peak area increased for the reconstituted samples

460 when compared to freeze-dried samples, meaning that the powder liposomes exhibit a

461 higher retention of estragole than their aqueous dispersed forms. Compared to Est-CL,

462 the encapsulation of estragole in lipid vesicles was improved with Est-DCL 75 and Est-

463 DCL 100 while the HP-ß-CD inclusion complex showed the higher retention of estragole

464 (Figure 3). Reconstituted batches were then considered for the release study and 465 determination of the $\mathrm{LC} \mathrm{m}_{\mathrm{Est}} / \mathrm{m}_{\text {powder }}$ of estragole.

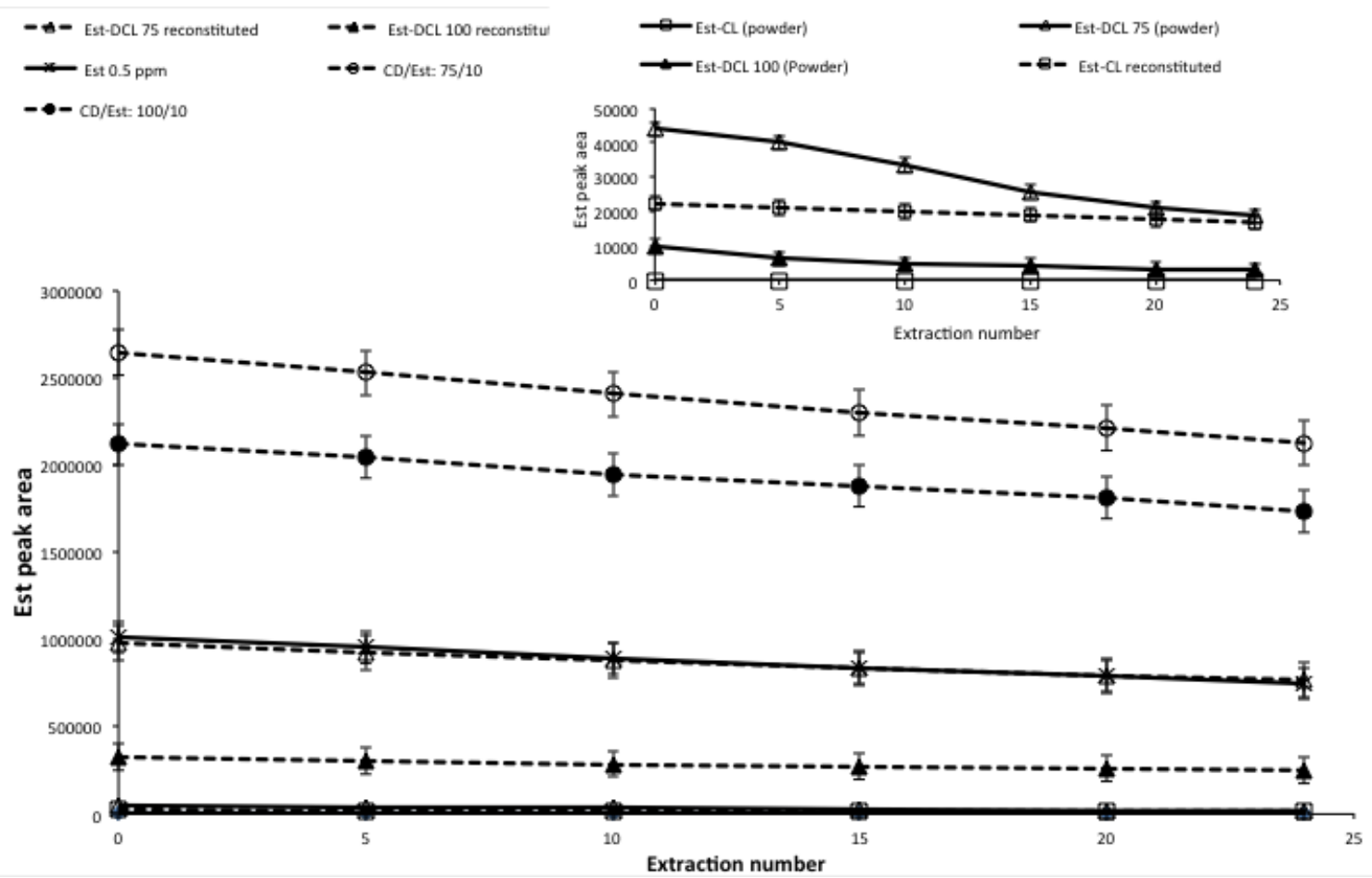

467 Figure 3: The estragole peak areas of the external standard ( $0.5 \mathrm{ppm}$ of Est in water), inclusion 468 complex HP-ß-CD:Est (75:10 and 100:10 molar ratios in water) and Est loaded liposomes (CL 469 and DCL in powder or reconstituted in water). The insert represents the peak areas for CL and DCL in powder form and CL reconstituted in water.

472 Figure 4 resumes the percentage of remaining estragole from the reference solution $(0.5$

473 ppm of estragole in water), HP-ß-CD inclusion complex (75:10 and 100:10 molar ratio in

474 water) and liposomes (CL and DCL reconstituted in water). The remaining percentage of 
475 estragole in the inclusion complex, Est-CL and Est-DCL suspensions was higher than

476 that of the reference solution. After 24 extractions $(24 \mathrm{~h})$, the remaining percentage of Est

477 was 81, 80, 78, 77 and 75\% for HP-ß-CD:Est 100:10, HP-ß-CD:Est 75:10, Est-DCL 75,

478 Est-DCL 100 and Est-CL, respectively.

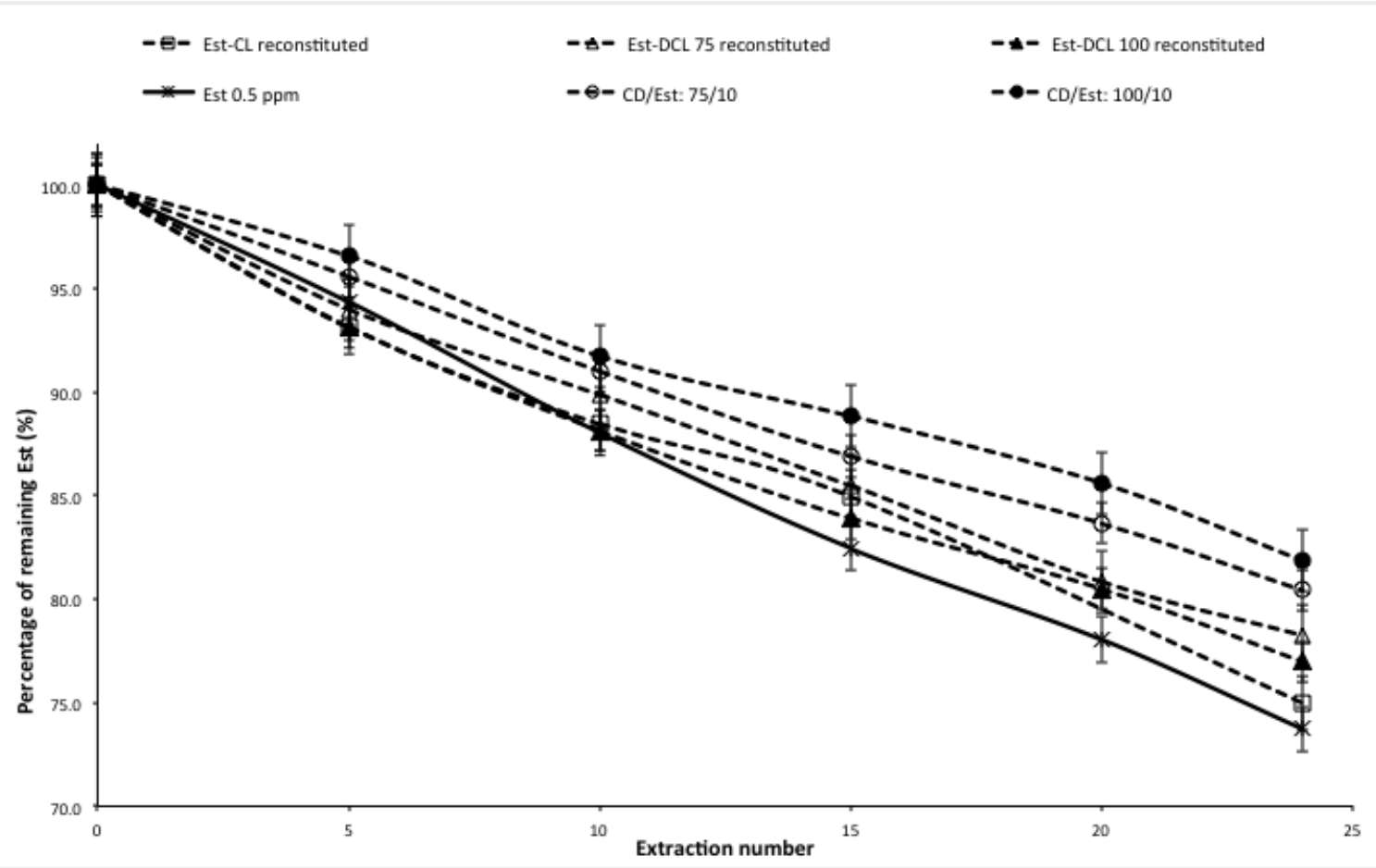

480 Figure 4: The percentage of remaining Est from Est external standard ( $0.5 \mathrm{ppm}$ of estragole in 481 water), inclusion complex HP-ß3-CD:Est (75:10 and 100:10 molar ratios in water) and estragole 482 loaded liposomes (CL and DCL reconstituted in water). 
口Est-CL reconstituted $\triangle$ Est-DCL 75 reconstituted $\boldsymbol{\Delta}$ Est-DCL 100 reconstituted X Est 0.5 ppm O CD/Est: $75 / 10 \quad$ CD/Est: $100 / 10$

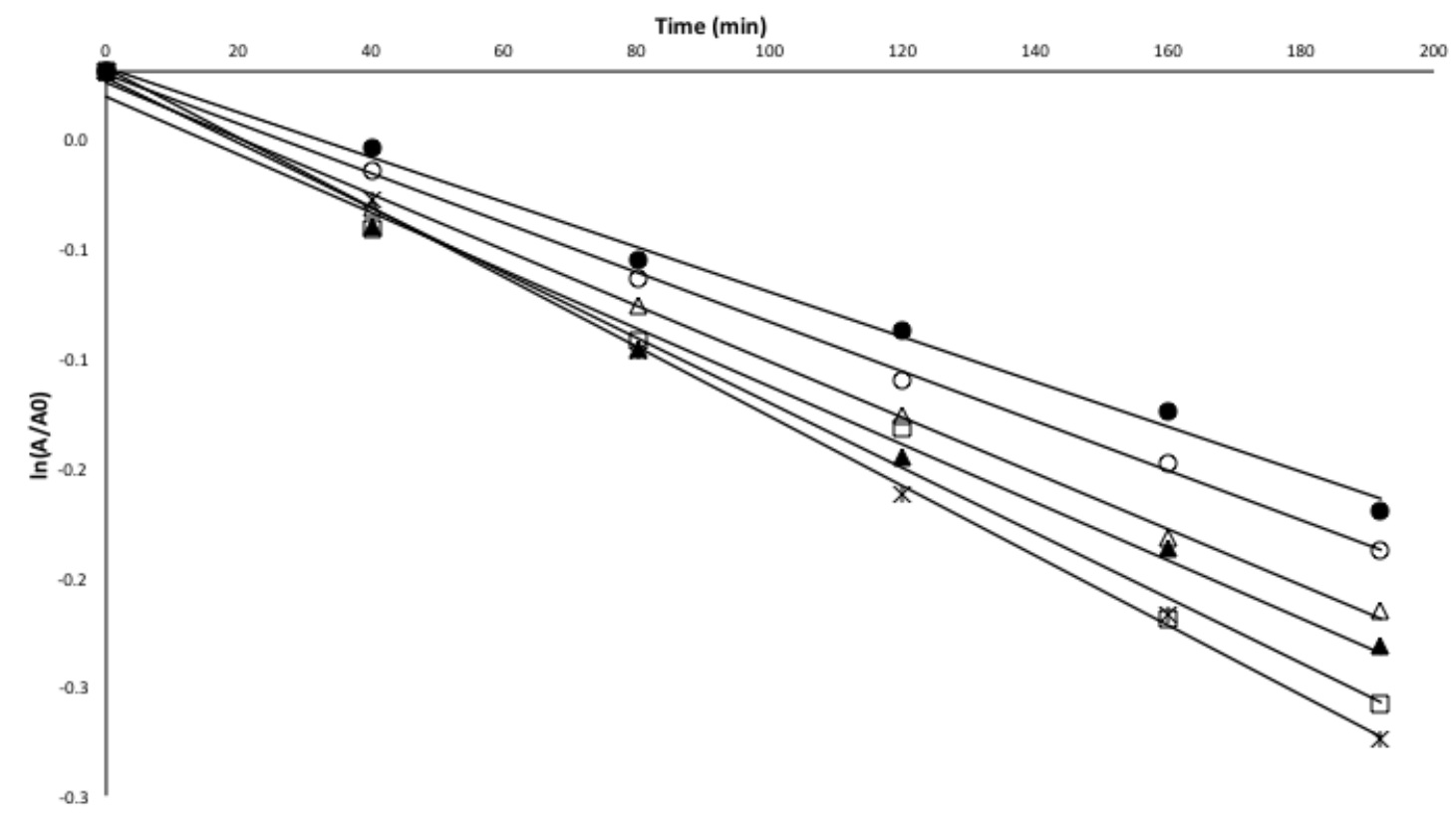

Figure 5 : The plot of $\ln \left(\mathrm{A}_{t} / \mathrm{A}_{0}\right)$ as a function of time for Est external standard $(0.5 \mathrm{ppm}$ of estragole in water), inclusion complex HP- $\beta-C D$ :Est (75:10 and 100:10 molar ratios in water) and estragole loaded liposomes (CL and DCL reconstituted in water).

488 The release rate constant was calculated according to equation 7 and the values are

489 presented in Table 4. The retention of estragole was improved by $1.6,1.4,1.3$ and 1.2

490 times for HP-ß-CD/Est 100:10, HP-ß-CD/Est 75:10, reconstituted Est-DCL 75 and 491 reconstituted Est-DCL 100 compared to free estragole (0.5ppm).

493 Table 4: Release rate constants of free estragole, HP-ß-CD/Est inclusion complex, Est-CL and 494 Est-DCL formulations

\begin{tabular}{|l|c|}
\hline & $\begin{array}{l}\text { Release rate constant K } \\
\left(\mathbf{m i n}^{-\mathbf{1}}\right)\end{array}$ \\
\hline Est 0.5 ppm & 0.013 \\
\hline HP-ß-CD/Est 100:10 & 0.008 \\
\hline HP-ß-CD/Est 75:10 & 0.009 \\
\hline Est DCL 75 reconstituted & 0.010 \\
\hline
\end{tabular}




\begin{tabular}{|l|l|}
\hline Est DCL 100 reconstituted & 0.011 \\
\hline Est-CL reconstituted & 0.012 \\
\hline
\end{tabular}

498 The incorporation of a volatile drug from a delivery system and its release could be 499 affected by its volatility. For that, the vapor-liquid partition coefficient $\left(\mathrm{H}_{\mathrm{C}}\right)$ of estragole

500 was determined using $\mathrm{HS}-\mathrm{GC}$ at 30 and $60^{\circ} \mathrm{C}$. The $\mathrm{H}_{\mathrm{C}}$ value of estragole was 0.03 at $30^{\circ} \mathrm{C}$

501 and increased to 0.07 at $60^{\circ} \mathrm{C}$. Hence, the volatility of estragole increased with

502 temperature. Thus, the HP- $\beta-C D /$ Est inclusion complex, CL or DCL improved the

503 retention of estragole and controlled its release. These results were in agreement with

504 Kfoury et al., [41] who showed that $\beta-C D$ derivatives improved the complexation in CDs

505 of essential oils components such as $\alpha$-pinene, mycrene, limonene, $p$-cymene and 506 terpinene.

\section{3.6 Determination of loading capacity of estragole $\left(\mathrm{m}_{\mathrm{Est}} / \mathrm{m}_{\text {powder }}\right)$}

509 The amount of estragole in the inclusion complex obtained at both molar ratios (HP-B-

510 CD:Est 75:10 and 100:10) and in the reconstituted liposomes was quantified by SH-GC

511 after 6 months of storage at $4^{\circ} \mathrm{C}$. The LC values expressed as $\mathrm{m}_{\text {Est }} / \mathrm{m}_{\text {powder }}$ and calculated

512 using equation 12, are listed in Table 5. The LC value of estragole in Est-CL was $0.01 \mu \mathrm{g}$

513 of Est/mg of powder. The CL formulations contain small amount of estragole, which was

514 not detected by HPLC. The encapsulation of estragole in DCL system was improved with

515 LC values of 0.6 and $0.2 \mu \mathrm{g}$ of Est/mg of powder for Est-DCL 75 and Est-DCL 100,

516 respectively. However, the LC values of estragole in the inclusion complex HP-ß-CD/Est

$517 \quad 75: 10$ and 100:10 were 10.8 and $9.3 \mu \mathrm{g}$ of Est $/ \mathrm{mg}$ of powder, respectively. These values 
518 were higher than those of Est-DCL 75 and Est-DCL 100. These results suggest that DCL

519 system improve the encapsulation of estragole compared to CL. The inclusion complex

520 HP-B-CD/Est showed the best ability to retain high amount of estragole. Among the three

521 systems, CD presents the higher LC followed by Est-DCL and Est-CL.

523 Table 5: Loading capacity $\mathrm{m}_{\text {Est }} / \mathrm{m}_{\text {powder }}$ in HP-ß-CD/Est inclusion complex and in Est-CL and 524 Est-DCL carrier systems after 6 months of storage at $4^{\circ} \mathrm{C}$.

\begin{tabular}{|c|c|}
\hline & LC $(\boldsymbol{\mu g}$ of Est/mg of powder) \\
\hline HP-ß-CD:Est 75:10 & 10.8 \\
\hline HP-ß-CD:Est 100:10 & 9.3 \\
\hline Est-CL & 0.01 \\
\hline Est-DCL 75 & 0.6 \\
\hline Est-DCL 100 & 0.2 \\
\hline
\end{tabular}

\subsection{Fluorescence anisotropy}

527 The fluorescence anisotropy measurements of DPH in liposomes give information on

528 membrane fluidity of liposomes membrane [42]. The DPH anisotropy values obtained at

52925 and $37^{\circ} \mathrm{C}$ for blank-CL, blank-DCL 75, blank-DCL 100, Est-CL, Est-DCL 75 and Est-

530 DCL 100 before and after freeze-drying are presented in Table 6.

531 Table 6: DPH fluorescence anisotropy measurements for blank-CL, blank-DCL, Est-CL and Est532 DCL made from Phospholipon $90 \mathrm{H}$ and cholesterol at 25 and $37^{\circ} \mathrm{C}$ before and after freeze-drying.

\begin{tabular}{|c|c|c|c|c|}
\hline & \multicolumn{2}{|c|}{ Before freeze-drying } & \multicolumn{2}{c|}{ After freeze-drying } \\
\hline & $\mathbf{2 5}^{\mathbf{}} \mathbf{C}$ & $\mathbf{3 7}^{\mathbf{}} \mathbf{C}$ & $\mathbf{2 5}^{\mathbf{C}} \mathbf{C}$ & $\mathbf{3 7}^{\mathbf{}} \mathbf{C}$ \\
\hline Blank-CL & $0.22 \pm 0.01$ & $0.17 \pm 0.00$ & n.d. & n.d. \\
\hline Blank-DCL 75 & $0.21 \pm 0.00$ & $0.17 \pm 0.00$ & $0.21 \pm 0.00$ & $0.17 \pm 0.00$ \\
\hline Blank-DCL 100 & $0.20 \pm 0.00$ & $0.18 \pm 0.01$ & $0.20 \pm 0.00$ & $0.18 \pm 0.00$ \\
\hline Est-CL & $0.22 \pm 0.01$ & $0.18 \pm 0.01$ & n.d. & n.d. \\
\hline Est-DCL 75 & $0.22 \pm 0.01$ & $0.18 \pm 0.01$ & $0.22 \pm 0.01$ & $0.18 \pm 0.01$ \\
\hline Est-DCL 100 & $0.21 \pm 0.00$ & $0.18 \pm 0.01$ & $0.21 \pm 0.01$ & $0.18 \pm 0.01$ \\
\hline
\end{tabular}


534 Values are expressed as the means of three repetitions \pm SD; n.d.: not determined

535 - $\mathrm{P}<0.05$ compared to those before freeze-drying

537 To the best of our knowledge, this is the first example of DPH fluorescence anisotropy

538 measurements conducted on freeze-dried DCLs. As expected, an increase of temperature

539 leads to an increase of membrane fluidity.

540 Compared to blank-CL, the presence of estragole or the inclusion complex HP- $\beta-\mathrm{CD} / \mathrm{Est}$

541 (75:10 and 100:10 molar ratio) did not affect the DPH anisotropy values at 25 and $37^{\circ} \mathrm{C}$.

542 The results obtained for Est-CL has been expected since a small amount of estragole was

543 encapsulated in CL, which could not affect the membrane fluidity. Gharib, et al., [43]

544 demonstrated that the presence of estragole in DPPC membrane, at molar ratios

545 Est:DPPC largely higher than those obtained in this study, reduced the DPH anisotropy

546 values at 28,41 and $50^{\circ} \mathrm{C}$ in a concentration-dependent manner.

547 Besides, dispersing the pellet of CL and DCLs with HP- $B-C D$ solution before freeze

548 drying did not affect the membrane fluidity, since the DPH anisotropy values remain

549 unchanged after freeze-drying for all batches (Table 6). These results proved that HP-ß-

$550 \mathrm{CD}$ could be used as membrane protectant during freeze-drying for $\mathrm{CL}$ and for DCL

551 system made from saturated phospholipids.

552

\section{Conclusion}

554 The characteristics of hydrogenated-liposomes (size, pdI, zeta potential and LR of

555 estragole) were maintained after freeze-drying using HP-B-CD as cryoprotectant for CL

556 and DCL systems. Moreover, HP-B-CD did not affect the fluidity of phospholipon 
$55790 \mathrm{H} /$ cholesterol. In addition, the presence of estragole within HP- $\beta-C D, C L$ or DCL 558 reduced its volatility and allowed its controlled release. The HP- $\beta-C D$ :Est inclusion 559 complex and Est-DCL system showed high retention of estragole and displayed a good

560 stability. These results suggest that freeze-dried CD inclusion complexes and DCL 561 systems could be considered as efficient carriers for essential oil components retention, 562 preservation, storage and controlled release of estragole.

\section{Acknowledgements}

565 The research was supported by the Research Funding Program at the Lebanese University 566 and the "Agence Universitaire de la Francophonie", projet PCSI (2018-2020) 


\section{References}

568 [1]. M. De Vincenzi, M. Silano, F. Maialetti, B Scazzocchio, Constituents of aromatic 569 plants: II. Estragole, Fitoterapia. 71 (2000) 725-729.

570 [2]. R.L. Smith, T.B. Adams, J. Doull, V.J. Feron, J.I. Goodman, L.J. Marnett, et al, 571 Safety assessment of allylalkoxybenzene derivatives used as flavouring substances 572 - methyl eugenol and estragole, Food Chem Toxicol. 40 (2002) 851-870.

573 [3]. R.J. Siqueira, P. J. Magalhaes, J.H. Leal-Cardoso, G. P. Duarte, S. Lahlou, 574 Cardiovascular effects of the essential oil of Croton zehntneri leaves and its main 575 constituents, anethole and estragole, in normotensive conscious rats, Life Sci. 78 576 (2006) $2365-2372$.

577 [4]. P.M. Soares, R.F. Lima, A.F. Pires, E.P. Souza, A. M. Assreuy, D.N. Criddle, 578 Effects of anethole and structural analogues on the contractility of rat isolated aorta: 579 Involvement of voltage-dependent Ca++-channels, Life Sci. 81 (2007) 1085-1093.

580 [5]. A.A. Shahat, A.Y. Ibrahim, S.F. Hendawy, E.A. Omer, F.M., Mammouda, F.H. 581 Abdel-Rahman, et al, Chemical composition, antimicrobial and antioxidant activities 582 of essential oils from organically cultivated fennel cultivars, Molecules. 16 (2011) $583 \quad 1366-1377$.

584 [6]. S. Shin, C.A. Kang, Antifungal activity of the essential oil of Agastache rugosa $585 \quad$ Kuntze and its synergism with ketoconazole, Lett. Appl. Microbiol. 36 (2003) 111$586 \quad 115$.

587 [7]. S. Shin, Essential oil compounds from Agastache rugosa as antifungal agent against 588 Trichophyton species, Arch. Pharm. Res. 27 (2004) 295-299. 
589 [8]. T.C. Andrade, S.G. De Lima, R.M. Freitas, M.S. Rocha, T. Islam, T.G. Da Silva, et

590 al, Isolation, characterization and evaluation of antimicrobial and cytotoxic activity

591 of estragole, obtained from the essential oil of Croton zehntneri (Euphorbiaceae), An.

$592 \quad$ Acad. Bras. Cienc. 87 (2015) 178-182.

593 [9]. C. Turek, F.C. Stintzing, Impact of different storage conditions on the quality of $594 \quad$ selected essential oils, Food Res. Int. 46 (2012) 341-353.

595 [10]. N.C. Bouvier-Brown, A.H. Goldstein, D.R. Worton, D.M. Matross, J.B. Gilman,

596 W.C. Kuster, et al, Methyl chavicol: characterization of its biogenic emission rate,

597 abundance, and oxidation products in the atmosphere, Atmos. Chem. Phys., 9 (2009)

$598 \quad 2061-2074$.

599 [11].P. Sutaphanit, P. Chitprasert, Optimisation of microencapsulation of holy basil 600 essential oil in gelatin by response surface methodology, Food Chem. 150 (2014) $601 \quad 313-320$.

602 [12].P. Chitprasert, P. Sutaphanit, Holy basil (Ocimum sanctum Linn.) essential oil 603 delivery to swine gastrointestinal tract using gelatin microcapsules coated with 604 aluminum carboxymethyl cellulose and beeswax, J. Agric. Food Chem. 62 (2014) $605 \quad 12641-12648$.

606 [13]. J. Viyoch, N. Pisutthanan, A. Faikreua, K. Nupangta, K. Wangtorpol, J. Ngokkuen, 607 Evaluation of in vitro antimicrobial activity of Thai basil oils and their micro608 emulsion formulas against Propionibacterium acnes, Int. J. Cosmet. Sci. 28 (2006) 609 $125-133$. 
610 [14].V. Ghosh, A. Mukherjee, N. Chandrasekaran, Ultrasonic emulsification of food611 grade nanoemulsion formulation and evaluation of its bactericidal activity, Ultrason. $612 \quad$ Sonochem. 20 (2013) 228-344.

613 [15]. M. Kfoury, L. Auezova, D. Landy, H. Greige-Gerges, S. Fourmentin, Effect of 614 cyclodextrins complexation on phenylpropanoids solubility and antioxydant activity, 615 Beilstein J. Org. Chem. 10 (2014) 2322-2331.

616 [16]. M. Kfoury, L. Auezova, S. Ruellan, H. Greige-Gerges, S. Fourmentin, Complexation 617 of estragole as pure compound and as main component of Basil and Tarragon 618 essential oils with cyclodextrins, Carbohydr. Polym. 118 (2015) 156,164.

619 [17]. M. Kfoury, A.L. Sahraoui, N. Bourdon, F. Laruelle, J. Fontaine, L. Auezova, L., et 620 al., Solubility, photostability and antifungal activity of phenylpropanoids 621 encapsulated in cyclodextrins, Food Chem. 196 (2016) 518-525.

622 [18].Y.F. Hsieh, T.L. Chen, Y.T. Wang, J.H. Chang, H.M. Chang, Properties of 623 liposomes prepared with various lipids, J. Food Sci. 67 (2002) 2808-2813.

624 [19]. R. Laridi, E.E. Kheadr, R.O. Benech, J.C. Vuillemard, C. Lacroix, I. Fliss, Liposome 625 encapsulated nisin Z: optimization, stability, and release during milk fermentation, 626 Int. Dairy J. 13 (2003) 325-336.

627 [20].L.M. Were, B.D. Bruce, P.M. Davidson, J. Weiss, Size, stability, and entrapment 628 efficiency of phospholipid nanocapsules containing polypeptide antimicrobials, $J$. $629 \quad$ Agric. Food Chem. 51(2003) 8073-8079.

630 [21]. T.M. Taylor, J. Weiss, P.M. Davidson, B.D. Bruce, Liposomal nanocapsules in food 631 science and agriculture, Crit. Reve. Food Sci. Nutri. 45 (2005) 587-605. 
632 [22]. J. Wolfe, G. Bryant, Freezing, drying, and/or vitrification of membrane- solute-water $633 \quad$ systems, Cryobiology 39 (1999) $103-129$.

634 [23].C. Chen, D. Han, C. Cai, X. Tang, An overview of liposome lyophilization and its 635 future potential, J. Control. Release 142, (2010) 299-311.

636 [24]. S. Kaddah, N. Khreich, F. Kaddah, C. Charcosset, H. Greige-Gerges, Cholesterol 637 modulates the liposome membrane fluidity and permeability for a hydrophilic 638 molecule, Food Chem. Toxicol. 113 (2018) 40-48.

639 [25]. R. Gharib, H. Greige-Gerges, S. Fourmentin, C. Charcosset, Hydroxypropyl-ß640 cyclodextrin as a membrane protectant during freezedrying of hydrogenated and 641 non-hydrogenated liposomes and molecule-incyclodextrin- in- liposomes: 642 Application to trans-anethole, Food Chem. 267 (2017) 67-74.

643 [26]. B. McCormack, G. Gregoriadis, Drugs-in-cyclodextrins-in-liposomes: a novel $644 \quad$ concept in drug delivery, Int. J. Pharm. 112 (1994) 249-258.

645 [27]. R. Gharib, H. Greige-Gerges, A. Jraij, L. Auezova, C. Charcosset, Preparation of 646 drug-in-cyclodextrin-in-liposomes at a large scaleusing a membrane contactor: 647 Application to trans-anethole, Carbohydr. Polym. 154 (2016) 276-286.

648 [28].R. Gharib, L. Auezova, C. Charcosset, H. Greige-Gerges, Drug-in-cyclodextrin-in649 liposomes as a carrier system for volatile essential oil components: application to $650 \quad$ anethole, Food Chem. 218 (2017) 365-371.

651 [29]. C. Sebaaly, C. Charcosset, S. Stainmesse, H. Fessi, H. Greige-gerges, Clove essential 652 oil-in-cyclodextrin-in-liposomes in the aqueous and lyophilized states: from 653 laboratory to large scale using a membrane contactor, Carbohydr. polym. 138 (2016) $654 \quad 75-85$. 
655 [30]. M. Kfoury, L. Auezova, S. Fourmentin, H. Greige-Gerges, Investigation of 656 monoterpenes complexation with hydroxypropyl-ß-cyclodextrin, J. Incl. Penom. $657 \quad$ Macrocycl. Chem. 80 (2014) 51-60.

658 [31].K.P. Whiting, C.J. Restall, P.F. Brain, Steroid hormone-induced effects on 659 membrane fluidity and their potential roles in non-genomic mechanisms, Life Sci. 67 $660 \quad$ (2000) 743-757.

661 [32].B. Kolb, L.S. Ettre, Static Headspace-Gas Chromatography: Theory andPractice 662 (Second edition). Hoboken, New Jersey: John Wiley \& Sons, Inc. (2006)

663 [33].Z. Hammoud, N. Khreich, L. Auezova, S. Fourmentin, A. Elaissari, H. Greige664 Gerges, Cyclodextrin-membrane interaction in drug delivery and membrane structure 665 maintenance, Int. J. Pharm. 564 (2019) 59-76

666 [34].F. Maestrelli, M.L. Gonzalez-Rodriguez, A.M. Rabasco, C. Ghelardini, P. Mura, 667 New "drug-in cyclodextrin-in deformable liposomes" formulations to improve the 668 therapeutic efficacy of local anaesthetics, Int. J. Pharm. 395 (2010) 222-231.

669 [35].M. Bragagni, F. Maestrelli, N. Mennini, C. Ghelardini, P. Mura, Liposomal 670 formulations of prilocaine: effect of complexation with hydroxypropyl- $\beta$ 671 cyclodextrin on drug anesthetic effect, J. Lip. Res. 20 (2010) 315-322.

672 [36]. G. Piel, M. Piette, V. Barillaro, D. Castagne, B. Evrard, L. Delattre, Betamethasone673 in-cyclodextrin-in-liposome: The effect of cyclodextrins on encapsulation efficiency 674 and release kinetics, Int. J. Pharm. 312 (2006) 75-82.

675 [37]. S.K. Jain, Y. Gupta, A. Jain, M. Bhola, Multivesicular liposomes bearing celecoxib$676 \quad \beta$-cyclodextrin complex for transdermal delivery, Drug Deliv. 14 (2007) 327-335. 
677 [38]. S.S. Dhule, P. Penfornis, T. Frazier, R. Walker, J. Feldman, G. Tan, et al, Curcumin678 loaded $\gamma$-cyclodextrin liposomal nanoparticles as delivery vehicles for osteosarcoma, $679 \quad$ Nanomedicine 8 (2012) 440-451.

680 [39]. H. Chen, J. Gao, F. Wang, W. Liang, Preparation, characterization and phar681 macokinetics of liposomes-encapsulated cyclodextrins inclusion complexes 682 forhydrophobic drug, Drug Deliv. 14 (2007) 201-208.

683 [40].F. Maestrelli, M.L. Gonzalez-Rodriguez, A.M. Rabasco, P. Mura, Effect of 684 preparation technique on the properties of liposomes encapsulating ketoprofen685 cyclodextrin complexes aimed for transdermal delivery, Int. J. Pharm. 312 (2006) $68653-60$.

687 [41]. M. Kfoury, L. Auezova, H. Greige-Gerges, S. Fourmentin, Promising applications of 688 cyclodextrins in food: Improvement ofessential oils retention, controlled release and 689 antiradical activity, Carbohydr. Polym. 131 (2015) 264-272.

690 [42]. G.N. Reiner, L.F. Fraceto, E. de Paula, M.A. Perillo, D.A. García, Effects of 691 Gabaergic Phenols on Phospholipid Bilayers as Evaluated by 1H-NMR, J. Biomater. $692 \quad$ Nanobiotechnol. 4 (2013) 28-34.

693 [43]. R. Gharib, A. Najjar, L. Auezova, C. Charcosset, H. Greige-Gerges, Interaction of 694 Selected Phenylpropenes with Dipalmitoylphosphatidylcholine Membrane and Their 695 Relevance to Antibacterial Activity, J. Membr. Biol. 250 (2017) 259-271. 